\title{
Stock Market Efficiency and Price Limits: Evidence from Korea’s Recent Expansion of Price Limits
}

\author{
H. R. Seddighi ${ }^{1}$ \\ Il-Hyun Yoon ${ }^{2}$
}

'Business School, University of Sunderland, St. Peter's Campus, St. Peters Way, Sunderland, Tyne and Wear SR6 ODD UK

${ }^{2}$ Division of Business Administration, Dongseo University, 47 Jurye-ro, Sasang-gu, Busan 47011 Korea Emaili ihyoon58@gdsu.dongseo.ac.kr

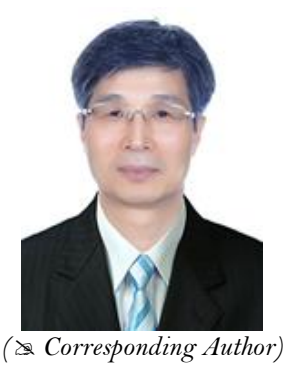

\begin{abstract}
This paper examines the efficiency of the Korean stock exchange market with reference to the recent relaxation of price limits effective on June 15, 2015 for the period from January 2012 to November 2017 and compares the efficiency between sub-periods before and after the police change which saw expansion of daily price limits from $15 \%$ to $30 \%$. The daily returns of the market index and 60 stocks selected from different industrial sectors are used to test the random walk hypothesis under two different price limits regime using the Lo-MacKinlay variance ratio tests and multiple variance ratio tests. The empirical evidence found that the market index showed weak form market efficiency along the lines of random walk hypothesis while individual sample stocks behaved differently according to the different price limits periods. The number of stocks following the random walk process increased under the $30 \%$ price limits regime in comparison with that under the $15 \%$ regime, indicating Korea's stock market appears to become more efficient as daily price limits are expanded although the findings are rather suggestive than definitive.
\end{abstract}

Keywords: Daily price limits, Efficient market hypothesis, Korean stock market, KOSPI, Multiple variance ratio tests, Random walk process JEL Classification: C12; G14.

Citation | H. R. Seddighi; Il-Hyun Yoon (2018). Stock Market Efficiency and Price Limits: Evidence from Korea's Recent Empirical Research, 5(2): 191-200. History:

Received: 26 July 2018

Revised: 30 August 2018

Accepted: 3 October 2018

Published: 6 November 2018

Licensed: This work is licensed under a Creative Commons

Attribution 3.0 License (c) $\mathbf{E}$

Publisher:Asian Online Journal Publishing Group
Contribution/Acknowledgement: Both authors contributed to the conception and design of the study.

Funding: This study received no specific financial support.

Competing Interests: The authors declare that they have no conflict of interests.

Transparency: The authors confirm that the manuscript is an honest, accurate, and transparent account of the study was reported; that no vital features of the study have been omitted; and that any discrepancies from the study as planned have been explained.

Ethical: This study follows all ethical practices during writing.

\section{Contents}

1. Introduction 


\section{Introduction}

Prediction of security prices is of great importance to investors in financial market to beat the market for better performance than others. Since the significant study by Fama (1965) in which he empirically presented that mutual fund investments for stocks of the Dow-Jones Industrial Average do not outperform randomly selected portfolio with no evidence of the fund managers having superiority to the average investors, a large number of researchers in both academic and industry sector have focused on the efficiency of stock markets across the world. In an efficient market, according to the efficient market hypothesis (EMH), stock prices "fully reflect" available information therefore investors cannot earn abnormal returns over the market average (Fama, 1970; 1991). The market efficiency has been tested with the random walk process where security prices moves randomly and serially independent. Therefore, under the random walk hypothesis, future stock prices cannot be predicted with the past price history since the relevant information would have already been fully reflected in an efficient market which is specifically known as weak form efficient market. ${ }^{1}$ Statistically speaking, random walk process is that stock prices move independently and their changes are identically distributed.

A large body of empirical research on random walk process test for examination of efficient market hypothesis has been done for the various stock markets in both developed and emerging economies since the works of Fama $(1965 ; 1970)$ and produced mixed results. Earlier studies on random walks of stock price movement were mainly conducted by use of conventional methods such as serial correlation, unit root test or runs test. However, since (Lo and MacKinlay, 1988) proposed a new method, the variance ratio test, to investigate the weekly stock returns in the US and rejected the random walk process for the US stock market, the variance ratio tests have been extensively used in recent studies because of its powerfulness.

Several studies have been devoted to the investigation on the random walk hypothesis for the Korean stock markets, such as Ayadi and Pyun (1994), Narayan and Smyth (2004) and Hasanov (2009) with mixed results. Some studies have been conducted to compare Korean stock market with other different stock markets in Asian region in terms of market efficiency using the market indexes. Huang (1995) rejected the random walks for Korean stock market while Hoque et al. (2007) and Kim and Shamsuddin (2008) suggested that Korean stock market is efficient.

Recently, Korean authority expanded daily limits of stock prices in Korea to 30 per cent on June 15 , 2015 for the first time since the government had eased the then-existing 12 per cent of price limits to 15 per cent in December 1998 in an effort to induce foreign direct investment into the country's financial market in order to deal with the financial crisis which broke out in late 1997. The Korea's price limit system has been steadily relaxed amid the persistent criticisms of market inefficiency it may cause due to the possible manipulation of stock prices and restriction of trading opportunities. As Korea joined the OECD, the daily stock price limits had been expanded since November 25, 1996 to 8 per cent from the previous 6 per cent limits. Following the 1997 Korean financial crisis, the price limits were relaxed to 12 per cent on March 2, 1998 and 15 per cent on December 7,1998 in an effort to encourage foreign investment into the country's capital market. ${ }^{2}$ This regime change of daily limits reinvigorated interest in the effect of stock price daily limits on the efficiency of stock markets. To prevent stock market from excessively fluctuating, some countries, including China, Taiwan and Japan, use daily price limits system where stock prices are allowed to move up or down within a maximum price range from the previous closing prices in a day. ${ }^{3}$

Although an abundance of research has been carried out with reference to the efficiency of stock markets, there are few studies on the effect of price limits on the stock market efficiency. Some of research on the price limits focused on the association between price limits and stock market volatility. Lee and Kim (1995) investigated the effects of price limits on the Korean stock market to find that price limits decreased stock price volatility over the period 1980-1989 while (Berkman and Lee, 2002) examined the effects of expansion of price limits on volatility and trading volume for Korean stocks for the period from April 1, 1994 to April 1, 1996 to find that expansion of price limits increased weekly volatility and decreased trading volume.

For studies on the stock price limits and market efficiency, Lee and Chung (1996) tested 30 stocks randomly selected from Korean stock exchange to find that the price limits system results in a lower volatility and that Korean stock market seems to be inefficient because of the biased price movements due to the price limits. Later, Ryoo and Smith (2002) examined the random walk hypothesis for the Korean stock market with the use of multiple variance ratio tests for a sample of 55 actively traded stocks selected from different industries for the period March 1988 to December 1998 which saw five changes of daily price limits. As price limits are eased, more stocks are found to follow the random walk process. Lim and Brooks (2009) compared the effects of change in price limits on the stock market efficiency among Korea, China and Taiwan. Using the rolling bicorrelation test statistic on the daily market indexes, they suggested that price limits do not weaken market efficiency. However, their findings may have some drawback in that they used market indexes for analysis rather than individual stock prices because the price limits are imposed on the individual stock prices not the market index.

It would be of great interest to examine whether relaxed price limits regime in Korea stock market have contributed to the market efficiency as hoped by the authority. To fill the gap in the literature on this topic, this paper aims to investigate the effects of the recent widening of price limits on efficiency of the Korean stock market based on a random walk model.

Based on the methods of alternative variance ratio tests, this study uses 60 companies listed in the Korea Exchange selected from different industries as well as Korea Composite Stock Price Index (KOSPI). Daily closing stock prices for the sample companies are collected over the period from January 2, 2012 to November 30, 2017 , which is divided into two sub-periods of January 2, 2012 - June 14, 2015 and June 15, 2015 - November 30, 2017 for comparison of market efficiency between before and after the relaxed price limits effective on June 15,2015 .

${ }^{1}$ In EMH, according to the three available information set, there are three different efficient markets, i.e., weak form, semi-strong form, and strong form efficient market. For more details, refer to Fama (1970).

${ }^{2}$ Detailed explanation and history of daily price limits system in the Korean stock market is well documented in Section III of Ryoo and Smith (2002).

${ }^{s}$ At present Japan's daily price limits are set in absolute yen from the previous day's closing price, for example, price limit for the stock with previous day's closing price of less than 1,000 yen is \pm 150 yen. In China and Taiwan, daily price limits of stocks are set at \pm 10 percent of the previous day's closing price (see http://www.jpx.co.jp/english/equities/trading/domestic/06.html, a http://english.sse.com.cn/tradmembership/rules/c/3977570.pdf, http://www.twse.com.tw/en/page/products/trading_rules/mechanismo1.html\#5). 
The rest of the paper is organized as follows. Section 2 discusses the research methodology to test the random walk hypothesis. The data used for analysis is presented in Section 3. Section 4 discusses empirical results and implications of the results before concluding the study in Section 5.

\section{Methodology}

Multiple variance ratio tests were employed to test the random walk process for daily stock returns in an attempt to investigate the effect of significant expansion of daily price limits on the efficiency of Korean stock market. ${ }^{4}$ Variance ratio tests proposed by Lo and MacKinlay (1988) have been popular and extensively used in testing the random walk process for examination of the market efficiency across the world including Korea (for example, Ayadi and Pyun (1994), Huang (1995), Ryoo and Smith (2002), Hoque et al. (2007) and Kim and Shamsuddin (2008). In an efficient (weak form) market, stock prices tend to follow a random walk process, hence stock prices cannot be predicted by the past information as all available information have been absorbed in current prices.

For the test of the market efficiency, the random walk model is used, defined as;

$$
P_{t}=\mu+P_{t-1}+\varepsilon_{t}
$$

or,

$$
\Delta P_{t}=r_{t}=P_{t}-P_{t-1}=\mu+\varepsilon_{t}
$$

where $\Delta P_{t}\left(r_{t}\right)$ is the continuously compounded rate of return for a stock at time $t, P_{t}$ and $P_{t-l}$ is the natural $\log$ form of the stock price at time $t$ and $t-1, \mu$ is a drift parameter, and $\varepsilon_{t}$ is a random disturbance term. Under the random walk hypothesis, $\varepsilon_{t}$ is independent and identically distributed (i.i.d.) and uncorrelated. If $\mu=0$, it is a random walk without drift, and if $\mu \neq 0$, it is a random walk with drift.

The variance ratio methodology is based on the idea that "the variance of random walk increments is linear in all sampling intervals", meaning that the "variance of $k$-period return of the time series $\left(y_{t}\right), r_{k}=y_{t}-y_{t-k}$, is $k$ times the variance of one-period return, $r_{t}=y_{t}-y_{t-\imath}$ " (Amélie and Darné, 2009). The variance ratio of $k$-period return, $\operatorname{VR}(\mathrm{k})$, is defined as:

$$
\operatorname{VR}(k)=\frac{\operatorname{Var}\left(r_{t}+r_{t-1}+\cdots+r_{t-k+1}\right) / k}{\operatorname{Var}\left(r_{t}\right)}=\frac{\operatorname{Var}\left(y_{t}-y_{t-k}\right) / k}{\operatorname{Var}\left(y_{t}-y_{t-1}\right)}=1+2 \sum_{i=1}^{k-1}\left(\frac{(k-i)}{k}\right) \rho_{i}
$$

where $\rho_{i}$ is the $i^{\text {th }}$ lag autocorrelation coefficient of (Malkiel and Fama).

$\operatorname{VR}(k)$ is a linear association of the first $(k-1)$ autocorrelation coefficients. When returns are not correlated over time, $\operatorname{Var}\left(r_{t}+r_{t-1}+\cdots+r_{t-k+1}\right)$ should be $k \operatorname{Var}\left(r_{t}\right)$, i.e., $\operatorname{VR}(k)=1$. The variance ratio test is a test of $H_{o}$ : $\rho_{l}=\cdots=\rho_{k}=0$, i.e., returns are serially uncorrelated. Consequently, it tests the hypothesis that the return of a time series $\left(y_{t}\right), r_{t}=y_{t}-y_{t-1}$, follows a random walk.

Two test statistics for the random walk process are estimated according to the assumptions of the data series. Under the assumption of homoscedasticity (i.e., i.i.d.), the test statistic $Z_{1}(k)$ for the null hypothesis of $\mathrm{V}(k)=1$, is given by

$$
Z_{1}(k)=\frac{V R(r ; k)-1}{\varphi(k)^{1 / 2}}
$$

where $\varphi(k)$ is asymptotic variance and defined by

$$
\varphi(k)=\frac{2(2 k-1)(k-1)}{3 k T}
$$

Under the assumption of conditional heteroscedasticity, the heteroscedasticity robust test statistic $\mathrm{Z}_{2}(\mathrm{k})$ for the null hypothesis of $\mathrm{V}(k)=1$, is given by

where

$$
Z_{2}(k)=\frac{V R(r ; k)-1}{\varphi^{\prime}(k)^{1 / 2}}
$$

$$
\begin{gathered}
\varphi^{\prime}(k)=\sum_{j=1}^{k-1}\left[\frac{2(k-j)}{k}\right]^{2} \delta(j) \\
\delta(j)=\left\{\sum_{t=j+1}^{T}\left(r_{t}-\hat{\mu}\right)^{2}\left(r_{t-j}-\hat{\mu}\right)^{2}\right\} \div\left\{\left[\sum_{t=1}^{T}\left(r_{t}-\hat{\mu}\right)^{2}\right]^{2}\right\}
\end{gathered}
$$

The Lo-MacKinlay variance ratio tests are designed to test the null hypothesis for an individual value of the holding period $k$. However, since the null hypothesis needs to be tested for all holding periods of $k$, the tests should be conducted jointly over a set of holding periods. To overcome the weakness of ignoring the joint nature of testing (Lo and MacKinlay, 1988) tests, this study employed the multiple variance ratio tests proposed by both Chow and Denning (1993) and Richardson and Smith (1991). The multiple variance ratio tests consider the joint null hypothesis $H_{o i}: V R\left(k_{i}\right)=1$ for all $i=1, \cdots, m$, against the alternative $H_{l i}: V R\left(k_{i}\right) \neq 1$ for any $i=1, \cdots, m$.

For the tests of the joint null hypothesis, the test statistic developed by Chow and Denning (1993) is defined as

$M_{1}=\sqrt{T} \max _{1 \leq i \leq m}\left|Z_{1}\left(k_{i}\right)\right|$

where $Z_{l}\left(k_{i}\right)$ is defined in Equation (4). The decision-making for the null hypothesis is based on the maximum absolute value of the individual variance ratio statistics. The studentised maximum modulus (SMM) distribution with $m$ parameters and $T$ degrees of freedom at $\alpha$ significance level, i.e., $\operatorname{SMM}(\alpha, m, T)$, are applied in the tests. Similarly, the heteroscedasticity robust statistic $\mathrm{M}_{2}$ is given as

$M_{2}=\sqrt{T} \max _{1 \leq i \leq m}\left|Z_{2}\left(k_{i}\right)\right|$

where $Z_{o}\left(k_{i}\right)$ is defined in Equation (6). The random walk hypothesis is rejected if the maximum absolute value, $M_{l}$ or $M_{2}$, is greater than the critical value of SMM at a chosen level of significance.

Alternatively, we used another joint test developed by Richardson and Smith (1991) which uses the Wald statistic defined in Equation (11).

$R S(k)=T\left(R-1_{k}\right)^{\prime} \varphi^{-1}\left(R-1_{k}\right)$

where $\mathrm{R}$ is the $(k+1)$ vector of sample $\mathrm{k}$ variance ratios, $1_{k}$ is the $(k \times 1)$ unit vector, and $\varphi$ is the covariance matrix of R. The $R S(k)$ statistic is based on the chi-squared distribution with $k$ degrees of freedom.

${ }_{4}^{4}$ Variance ratio, individual and multiple, tests are well documented in Amélie and Darné (2009). 
This test is argued to be more powerful than multiple variance ratio tests of Chow and Denning (1993); Fong et al. (1997). However, this test is useful only in the homoscedastic tests (Amélie and Darné, 2009). Hence Richardson-Smith tests were only applied under no heteroscedastic assumption in this study.

\section{Data Analysis}

For the analysis on the efficiency of Korea's stock market, this study used daily closing prices of 60 stocks listed in the Korea Exchange as well as the market index, KOSPI. The sample period runs from January 2012 to November 30, 2017, corresponding to 1,459 observations and the data were obtained from Yahoo Finance database. The period is divided into two sub-periods i.e., the period for January 2, 2012 to June 14, 2015 under daily price limits regime of $15 \%$ and the period for June 15, 2015 to November 30, 2017 under the 30\% daily price limits regime with 850 and 609 observations, respectively.

As of November 30, 2017, the number of companies listed in KOSPI market is 770 with total number of listed stocks being 883 and its market capitalisation amounts to 1,607 trillion won, equivalent of 1,477 billion dollars. Korea's stock market is composed of a number of key industries as shown in Table 1. Special care is taken to select the samples that are actively traded so as to represent the industries well, considering the number of stocks belonging to the industry and their market capitalisation with respect to aggregate market capitalisation. Accordingly, six stocks come from Finance industry, five stocks are chosen from each of industries such as Chemicals, Services, Distribution, Electrical \& Electronic Equipment and Transport Equipment. In the industry of Iron \& Metal Products, Medical Supplies, Machinery, Food \& Beverages and Construction, four stocks are sampled from each industry and two stocks are selected from each of Electricity \& Gas, Communication and Transport \& Storage. Three stocks are chosen from Textile \& Wearing Apparel, Non-metallic Mineral Products and Other Manufacture. Table 2 reports sample stocks classified by industry, each sample's market capitalisation and the number of listed shares with its percentage vis-à-vis those of aggregate market and ratio held by foreign investors. A sample of 60 stocks constitutes 56 per cent of total market capitalisation and 25 per cent of total number of shares listed in Korea's stock market.

Table-1. Overview of listed companies by industry (as of Nov 2017)

\begin{tabular}{|c|c|c|c|c|}
\hline Industrial Classification & $\begin{array}{l}\text { No of Listed } \\
\text { Companies }\end{array}$ & $\begin{array}{l}\text { No of Listed Shares } \\
\text { (Thousand) }\end{array}$ & $\begin{array}{l}\text { Capital Stock Listed } \\
\text { (Mil Won, \%) }\end{array}$ & $\begin{array}{l}\text { Market } \\
\text { (Mil Won, \%) }\end{array}$ \\
\hline KOSPI Market & 770 & $42,313,258$ & $107,486,916(100.00)$ & $1,607,169,301(100.00)$ \\
\hline Finance & 115 & $12,294,653$ & $42,554,280(39.59)$ & $316,091,598(19.67)$ \\
\hline Chemicals & 93 & $2,927,784$ & $6,348,142(5.91)$ & $163,974,550(10.20)$ \\
\hline Services & 73 & $3,124,206$ & $3,648,543(3.39)$ & $123,069,555(7.66)$ \\
\hline Distribution & 59 & $2,966,748$ & $4,914,762(4.57)$ & $82,679,537(5.14)$ \\
\hline $\begin{array}{l}\text { Electrical and Electronic } \\
\text { Equipment }\end{array}$ & 54 & 3,943,099 & $10,151,032(9.44)$ & $491,579,552(30.59)$ \\
\hline Transport Equipment & 54 & $3,178,910$ & $9,948,482(9.26)$ & $120,227,496(7.48)$ \\
\hline Iron \& Metal Products & 45 & $1,422,641$ & $3,151,818(2.93)$ & $57,171,528(3.56)$ \\
\hline Medical Supplies & 41 & $1,250,815$ & $1,268,274(1.18)$ & $51,604,430(3.21)$ \\
\hline Machinery & 41 & $1,927,585$ & $2,594,990(2.41)$ & $19,858,694(1.24)$ \\
\hline Foods \& Beverages & 39 & $1,300,254$ & $1,312,162(1.22)$ & $34,295,813(2.13)$ \\
\hline Construction & 31 & $1,626,633$ & $5,586,149(5.20)$ & $20,468,693(1.27)$ \\
\hline Textile \& Wearing Apparel & 25 & 624,299 & $527,899(0.49)$ & $6,198,328(0.39)$ \\
\hline $\begin{array}{ll}\text { Non-metallic } & \text { Mineral } \\
\text { Products } & \end{array}$ & 22 & 682,581 & $1,257,597(1.17)$ & $8,128,040(0.51)$ \\
\hline Transport \& Storage & 21 & $1,443,321$ & $3,655,461(3.40)$ & $20,204,123(1.26)$ \\
\hline Other Manufacture & 12 & 468,236 & $1,176,699(1.09)$ & $18,784,711(1.17)$ \\
\hline Electricity \& Gas & 10 & 808,503 & $3,930,721(3.66)$ & $31,098,019(1.93)$ \\
\hline Communication & 4 & 865,739 & $4,226,743(3.93)$ & $35,462,277(2.21)$ \\
\hline Others & 31 & $1,457,248$ & $1,233,161(1.15)$ & $6,272,357(0.39)$ \\
\hline
\end{tabular}

Note: Finance includes Banks, Securities, Insurance and Other Financial Companies.

Others include Paper \& Wood, Medical \& Precision Machines, Fisheries Industry, and Mining Industry.

The continuously compounded rate of return for market index and each sample stock for the sample period are used for the empirical analysis and its descriptive statistics are summarized in Table 3 . The average mean of daily returns for 60 stocks $(0.012 \%)$, as well as the index (0.021\%), is positive for the entire sample period, reflecting the overall rise of the Korean stock market during the sample period. The average for the period after the expansion of daily price limits on June 15, $2015(0.0117 \%)$ is higher than that of period before the change of price limits $(0.0113 \%)$. As for the volatility of stock returns, the average standard deviation of the period under the $30 \%$ price limits regime is 0.0219 and appears to be more volatile than the period with the $15 \%$ of price limits $(0.0213)$. In contrast, standard deviation of KOSPI in the $15 \%$ regime of daily price limits (0.0078) is higher than that of the $30 \%$ price limits regime period $(0.0074) .{ }^{5}$ 
Table-2. Sample companies

\begin{tabular}{|c|c|c|c|c|c|}
\hline \multirow{2}{*}{ Companies } & \multicolumn{2}{|l|}{ Market Cap } & \multicolumn{2}{|c|}{ No of listed shares } & \multirow{2}{*}{$\begin{array}{l}\text { Ratio held by } \\
\text { Foreigner }\end{array}$} \\
\hline & Million Won & $(\%)$ & Thousand & $(\%)$ & \\
\hline \multicolumn{6}{|l|}{ Finance } \\
\hline Samsung Life Insurance Co., Ltd. & $25,600,000$ & 1.59 & $200,000,000$ & 0.47 & 16.59 \\
\hline KB Financial Group Inc & $25,044,881$ & 1.56 & $418,111,537$ & 0.99 & 69.21 \\
\hline Shinhan Financial Group Co., Ltd. & $22,951,260$ & 1.43 & $474,199,587$ & 1.12 & 69.05 \\
\hline Woori Bank Co., Ltd. & $10,951,200$ & 0.68 & $676,000,000$ & 1.60 & 27.39 \\
\hline Mirae Asset Daewoo Co., Ltd. & $6,829,743$ & 0.42 & $666,316,408$ & 1.57 & 11.81 \\
\hline Hanwha Life Insurance Co., Ltd. & $6,479,234$ & 0.4 & $868,530,000$ & 2.05 & 19.29 \\
\hline \multicolumn{6}{|l|}{ Chemicals } \\
\hline LG Chem, Ltd. & $29,472,303$ & 1.83 & $70,592,343$ & 0.17 & 40.23 \\
\hline S-Oil Corporation & $13,453,644$ & 0.84 & $112,582,792$ & 0.27 & 77.5 \\
\hline Lotte Chemical Corporation & $12,270,600$ & 0.76 & $34,275,419$ & 0.08 & 31.89 \\
\hline Hyosung Corporation & $4,740,856$ & 0.29 & $35,117,455$ & 0.08 & 23.24 \\
\hline Hankook Cosmetics Manufacturing Co., Ltd & 250,166 & 0.02 & $4,532,000$ & 0.01 & 0.62 \\
\hline Services & & & & & \\
\hline Naver Corporation & $26,370,143$ & 1.64 & $32,962,679$ & 0.08 & 59.29 \\
\hline NCsoft Corporation & $9,576,383$ & 0.6 & $21,939,022$ & 0.05 & 43.25 \\
\hline Kakao Corp. & $9,267,968$ & 0.58 & $67,897,203$ & 0.16 & 22.32 \\
\hline Kangwon Land, Inc. & $7,947,890$ & 0.49 & $213,940,500$ & 0.51 & 29.38 \\
\hline Cheil Worldwide Inc. & $2,312,329$ & 0.14 & $115,041,225$ & 0.27 & 33.41 \\
\hline Distribution & & & & & \\
\hline E-MART Inc. & $7,624,036$ & 0.47 & $27,875,819$ & 0.07 & 49.25 \\
\hline Lotte Shopping Co., Ltd. & $5,905,630$ & 0.37 & $28,122,047$ & 0.07 & 17.49 \\
\hline Hotel Shilla Co.,Ltd & $3,324,316$ & 0.21 & $39,248,121$ & 0.09 & 22.38 \\
\hline Shinsegae Inc. & $2,825,567$ & 0.18 & $9,845,181$ & 0.02 & 23.37 \\
\hline Hyundai Department Store Co., Ltd. & $2,288,759$ & 0.14 & $23,402,441$ & 0.06 & 25.82 \\
\hline Electrical and Electronic Equipment & & & & & \\
\hline Samsung Electronics Co., Ltd. & $327,910,175$ & 20.4 & $129,098,494$ & 0.31 & 53.25 \\
\hline SK Hynix Inc. & $55,910,582$ & 3.48 & $728,002,365$ & 1.72 & 48.21 \\
\hline LG Electronics Inc. & $14,728,303$ & 0.92 & $163,647,814$ & 0.39 & 32.99 \\
\hline Taihan Electric Wire Co., Ltd. & 984,944 & 0.06 & $856,473,009$ & 2.02 & 0.65 \\
\hline sindoh Co., Ltd. & 652,178 & 0.04 & $10,080,029$ & 0.02 & 25.85 \\
\hline Transport Equipment & & & & & \\
\hline Hyundai Motor Company & $36,235,481$ & 2.25 & $220,276,479$ & 0.52 & 45.34 \\
\hline Hyundai Mobis Co., Ltd & $26,623,547$ & 1.66 & $97,343,863$ & 0.23 & 48.55 \\
\hline Kia Motors Corporation & $13,640,477$ & 0.85 & $405,363,347$ & 0.96 & 37.87 \\
\hline Korea Aerospace Industries, Ltd. & $4,883,503$ & 0.3 & $97,475,107$ & 0.23 & 18.64 \\
\hline Samsung Heavy Industries Co., Ltd & $4,660,500$ & 0.29 & $390,000,000$ & 0.92 & 19.87 \\
\hline Iron \& Metal Products & & & & & \\
\hline POSCO & $29,207,590$ & 1.82 & $87,186,835$ & 0.21 & 55.76 \\
\hline Korea Zinc Co., Ltd. & $9,180,255$ & 0.57 & $18,870,000$ & 0.04 & 24.21 \\
\hline Hyundai Steel Company & $8,006,747$ & 0.5 & $133,445,785$ & 0.32 & 24.91 \\
\hline Dongkuk Steel Mill Company Limited & $1,068,847$ & 0.07 & $95,432,737$ & 0.23 & 29.81 \\
\hline Medical Supplies & & & & & \\
\hline Hanmi Pharm. Co., Ltd & $6,352,004$ & 0.4 & $11,163,452$ & 0.03 & 12.34 \\
\hline Yuhan Corporation & $2,566,497$ & 0.16 & $11,665,896$ & 0.03 & 24.47 \\
\hline Green Cross Corporation & $2,512,606$ & 0.16 & $11,686,538$ & 0.03 & 25.94 \\
\hline Daewoong Pharmaceutical Co., Ltd. & $1,575,774$ & 0.1 & $11,586,575$ & 0.03 & 5.93 \\
\hline Machinery & & & & & \\
\hline Hanon Systems & $7,046,160$ & 0.44 & $533,800,000$ & 1.26 & 19.53 \\
\hline Doosan Infracore Co., Ltd. & $1,842,780$ & 0.11 & $207,520,257$ & 0.49 & 11.3 \\
\hline Doosan Heavy Industries \& Construction Co., Ltd. & \begin{tabular}{l|l}
$1,745,973$ \\
\end{tabular} & 0.11 & $106,461,787$ & 0.25 & 8.25 \\
\hline Hyundai Elevator Co., Ltd. & $1,298,133$ & 0.08 & $24,632,513$ & 0.06 & 32.86 \\
\hline Foods \& Beverages & & & & & \\
\hline CJ Cheiljedang Corporation & $5,280,768$ & 0.33 & $13,168,998$ & 0.03 & 27.62 \\
\hline Ottogi Corporation & $2,731,360$ & 0.17 & $3,440,000$ & 0.01 & 18.7 \\
\hline NongShim Co., Ltd. & $2,223,206$ & 0.14 & $6,082,642$ & 0.01 & 21.43 \\
\hline Samyang Corporation & 986,792 & 0.06 & $10,289,803$ & 0.02 & 3.94 \\
\hline Construction & & & & & \\
\hline Hyundai Engineering \& Construction Co., Ltd. & \begin{tabular}{l|l|}
$3,903,020$ \\
\end{tabular} & 0.24 & $111,355,765$ & 0.26 & 29.5 \\
\hline Daelim Industrial Co., Ltd. & $2,877,960$ & 0.18 & $34,800,000$ & 0.08 & 34.01 \\
\hline Daewoo Engineering \& Construction Co., Ltd. & $2,331,643$ & 0.15 & $415,622,638$ & 0.98 & 12.34 \\
\hline GS Engineering \& Construction Corporation & $1,953,150$ & 0.12 & $71,675,237$ & 0.17 & 11.6 \\
\hline Electricity \& Gas & & & & & \\
\hline Korea Electric Power Corporation & $24,073,653$ & 1.5 & $641,964,077$ & 1.52 & 31.15 \\
\hline Korea Gas Corporation & $4,084,850$ & 0.25 & $92,313,000$ & 0.22 & 10.15 \\
\hline Communication & & & & & \\
\hline SK Telecom Co., Ltd. & $21,316,868$ & 1.33 & $80,745,711$ & 0.19 & 41.78 \\
\hline KT Corporation & $7,950,855$ & 0.49 & $261,111,808$ & 0.62 & 49 \\
\hline Transport \& Storage & & & & & \\
\hline Hyundai Glovis Co., Ltd. & $5,493,750$ & 0.34 & $37,500,000$ & 0.09 & 32.18 \\
\hline Korean Air Lines Co., Ltd. & $2,973,379$ & 0.19 & $94,844,634$ & 0.22 & 16.06 \\
\hline Textile \& Wearing Apparel & & & & & \\
\hline LF Corp. & 897,668 & 0.06 & $29,240,000$ & 0.07 & 37.73 \\
\hline Non-metallic Mineral Products & & & & & \\
\hline Ssangyong Cement Industrial Co., Ltd. & $2,055,747$ & 0.13 & $100,771,919$ & 0.24 & 3.73 \\
\hline Other Manufacture & & & & & \\
\hline KT\&G Corporation & $16,749,685$ & 1.04 & $137,292,497$ & 0.32 & 53.24 \\
\hline Total & $902,004,316$ & 56.13 & $10,633,963,390$ & 25.13 & \\
\hline
\end{tabular}

Source: Korea Exchange website (http://www.krx.co.kr/main/main.jsp ) 
Out of 60 stocks, daily returns of 19 stocks have negative skewness with distributions skewed to the right. Skewness measures how symmetric the observations are around the mean. For a normal distribution, the skewness is 0 . Kurtosis coefficients of all stock returns are greater than 3, indicating the leptokurtosis characteristics with fat-tailed distributions. As a result, all data are not believed to be normally distributed, which can be also confirmed by the Jarque-Bera test for normality.

Table-3. Descriptive statistics for daily returns of index and stocks

\begin{tabular}{|c|c|c|c|c|c|c|c|}
\hline Company & Mean & Std. Dev. & Skewness & Kurtosis & Jarque-Bera & Prob & Obs \\
\hline KOPSI & 0.000209 & 0.007677 & -0.13721 & 4.722613 & 184.8443 & 0 & 1458 \\
\hline SAMSUNGLIFE & 0.000319 & 0.015837 & 0.315095 & 6.543054 & 786.7352 & 0 & 1458 \\
\hline KBFIN & 0.000347 & 0.015533 & 0.214527 & 3.750836 & 45.4314 & 0 & 1458 \\
\hline SHINHANFIN & 0.000138 & 0.01563 & 0.28115 & 4.330016 & 126.6713 & 0 & 1458 \\
\hline WOORIBK & 0.000382 & 0.018427 & 0.189501 & 8.17524 & 1635.8 & 0 & 1458 \\
\hline MIRAEASSET & $-6.66 \mathrm{E}-06$ & 0.020966 & 0.392167 & 6.541649 & 799.3765 & 0 & 1458 \\
\hline HANWHALIFE & $2.72 \mathrm{E}-05$ & 0.016577 & 0.162107 & 5.496956 & 385.1491 & 0 & 1458 \\
\hline LGCHEM & 0.000182 & 0.021007 & -0.186041 & 6.156657 & 613.7528 & 0 & 1458 \\
\hline S-OIL & 0.000119 & 0.019377 & 0.288715 & 5.831054 & 507.1586 & 0 & 1458 \\
\hline LOTTECHEM & 0.000125 & 0.024794 & -0.289786 & 5.405647 & 371.9748 & 0 & 1458 \\
\hline HYOSUNG & 0.000643 & 0.022677 & 0.082342 & 5.590436 & 409.3017 & 0 & 1458 \\
\hline HANKOOKCOS & 0.001834 & 0.043023 & 1.491198 & 9.666196 & 3239.97 & 0 & 1458 \\
\hline NAVER & 0.000781 & 0.027375 & 0.748076 & 60.98742 & 204410.3 & 0 & 1458 \\
\hline NCSOFT & 0.00025 & 0.026432 & -0.128478 & 5.770905 & 470.4445 & 0 & 1458 \\
\hline KAKAO & $6.75 \mathrm{E}-05$ & 0.023278 & 0.799622 & 7.496731 & 1383.774 & 0 & 1458 \\
\hline KANGWONLAND & 0.000191 & 0.017575 & 0.3718 & 5.68505 & 471.5681 & 0 & 1458 \\
\hline CHEILWORLDWIDE & $6.06 \mathrm{E}-05$ & 0.021144 & -0.096618 & 7.007528 & 977.9307 & 0 & 1458 \\
\hline E-MART & $7.56 \mathrm{E}-06$ & 0.018381 & 0.204654 & 4.052233 & 77.43965 & 0 & 1458 \\
\hline LOTTESHOPPING & -0.00032 & 0.020224 & -0.171025 & 8.229201 & 1668.288 & 0 & 1458 \\
\hline HOTELSHILLA & 0.000512 & 0.024411 & -0.107169 & 6.804839 & 882.2566 & 0 & 1458 \\
\hline SHINSEGAE & 0.000117 & 0.021877 & 0.611311 & 7.276117 & 1201.634 & 0 & 1458 \\
\hline HYUNDAISTORE & -0.00032 & 0.018277 & 0.381316 & 4.046029 & 101.804 & 0 & 1458 \\
\hline SAMSUNGELECT & 0.000587 & 0.016517 & -0.087436 & 4.896512 & 220.3609 & 0 & 1458 \\
\hline SKHYNIX & 0.000814 & 0.021522 & -0.071395 & 3.832229 & 43.31444 & 0 & 1458 \\
\hline LGELECT & 0.000115 & 0.019017 & 0.600833 & 6.596744 & 873.6196 & 0 & 1458 \\
\hline TAIHANELECT & -0.003102 & 0.036225 & -1.31431 & 36.07573 & 66880.5 & 0 & 1458 \\
\hline SINDOHCO & 0.000184 & 0.015464 & 0.086927 & 5.32571 & 330.4285 & 0 & 1458 \\
\hline HYUNDAIMOTOR & -0.000176 & 0.018203 & 0.011697 & 5.057263 & 257.1474 & 0 & 1458 \\
\hline HYUNDAIMOBIS & $-4.61 \mathrm{E}-05$ & 0.018527 & 0.107988 & 5.643242 & 427.2775 & 0 & 1458 \\
\hline KIAMOTORS & -0.000467 & 0.016821 & -0.040053 & 4.74995 & 186.4261 & 0 & 1458 \\
\hline KOREAAEROSPACE & 0.000166 & 0.023778 & 0.139853 & 10.43533 & 3363.26 & 0 & 1458 \\
\hline SAMSUNGHEAVY & -0.000496 & 0.024074 & 0.306583 & 4.838954 & 228.2817 & 0 & 1458 \\
\hline POSCO & $-7.92 \mathrm{E}-05$ & 0.016844 & 0.22126 & 4.698362 & 187.1256 & 0 & 1458 \\
\hline KOREAZINC & 0.000334 & 0.020201 & -0.24653 & 6.628705 & 814.6944 & 0 & 1458 \\
\hline HYUNDAISTEEL & -0.00031 & 0.019129 & 0.286007 & 4.296309 & 121.9628 & 0 & 1458 \\
\hline DONGKUKSTEEL & -0.000323 & 0.024342 & 0.253416 & 5.591266 & 423.521 & 0 & 1458 \\
\hline HANMIPHARM & 0.001642 & 0.031604 & 0.478023 & 11.24867 & 4188.99 & 0 & 1458 \\
\hline YUHAN & 0.000408 & 0.020855 & -0.390394 & 9.016523 & 2236.097 & 0 & 1458 \\
\hline GREENCROSS & 0.000295 & 0.022358 & 0.349194 & 7.562143 & 1294.029 & 0 & 1458 \\
\hline DAEWOONGPHARM & 0.001067 & 0.027472 & 0.559751 & 9.884005 & 2955.05 & 0 & 1458 \\
\hline HANONSYSTEMS & 0.000776 & 0.024959 & -0.012913 & 5.230211 & 302.2014 & 0 & 1458 \\
\hline DOOSANINFRACORE & -0.000483 & 0.027436 & 0.440325 & 8.392877 & 1813.914 & 0 & 1458 \\
\hline DOOSANHEAVY & -0.000938 & 0.023369 & 0.092154 & 5.372312 & 343.9564 & 0 & 1458 \\
\hline HYUNDAIELEVATOR & -0.000523 & 0.028584 & 0.668203 & 8.002758 & 1628.924 & 0 & 1458 \\
\hline CJCHEILJEDANG & 0.000211 & 0.017791 & 0.120747 & 4.21328 & 92.96984 & 0 & 1458 \\
\hline OTTOGI & 0.001129 & 0.023906 & 0.341965 & 5.395803 & 377.1137 & 0 & 1458 \\
\hline NONGSHIM & 0.000296 & 0.019986 & 0.310585 & 5.013822 & 269.8109 & 0 & 1458 \\
\hline SAMYANG & 0.000463 & 0.024049 & 0.855911 & 10.96519 & 4032.252 & 0 & 1458 \\
\hline HYUNDAIENGCON & -0.000493 & 0.020917 & 0.114031 & 5.261803 & 313.9416 & 0 & 1458 \\
\hline DAELIM & $-6.03 \mathrm{E}-05$ & 0.022966 & -0.003726 & 5.172659 & 286.7706 & 0 & 1458 \\
\hline DAEWOOENGCON & -0.000413 & 0.022764 & 0.108734 & 6.469954 & 734.3382 & 0 & 1458 \\
\hline GSENGCON & -0.000797 & 0.025995 & -0.161396 & 7.206933 & 1081.501 & 0 & 1458 \\
\hline KEPCO & 0.000275 & 0.016796 & -0.039169 & 4.918855 & 224.0545 & 0 & 1458 \\
\hline KOREAGAS & $7.50 \mathrm{E}-05$ & 0.019372 & 0.426826 & 4.926668 & 269.7768 & 0 & 1458 \\
\hline SKTELECOM & 0.000438 & 0.01565 & 0.102381 & 4.033367 & 67.41883 & 0 & 1458 \\
\hline KT & -0.000103 & 0.012309 & 0.273508 & 6.3605 & 704.2254 & 0 & 1458 \\
\hline HYUNDAIGLOVIS & -0.000178 & 0.021283 & -0.298002 & 7.681086 & 1352.768 & 0 & 1458 \\
\hline KAL & -0.000223 & 0.021332 & 0.512896 & 7.454483 & 1269.351 & 0 & 1458 \\
\hline LFCORP & -0.000203 & 0.018534 & 0.132134 & 5.45836 & 371.3873 & 0 & 1458 \\
\hline SSANGYONGCEMENT & 0.001279 & 0.028079 & 1.300272 & 17.79263 & 13704.27 & 0 & 1458 \\
\hline KT\&G & 0.000295 & 0.016533 & -0.087064 & 3.840069 & 44.7142 & 0 & 1458 \\
\hline Average of stocks & 0.000115 & 0.021640 & & & & & \\
\hline (15\% Regime Average) & 0.000113 & 0.021322 & & & & & \\
\hline (30\% Regime Average) & 0.000117 & 0.021876 & & & & & \\
\hline
\end{tabular}

Source: Outcome from Eviews 7

\section{Empirical Results}

In order to investigate the stock market efficiency in Korea, the variance ratio tests are performed, using Eviews statistical package, to test the random walk hypothesis for the daily return data of the index and 60 stock prices for the two periods of the different price limits regimes. The test periods are based on 5 observations per week and five intervals are set as “2, 5, 10, 15, 20”, spanning four weeks following (Ryoo and Smith, 2002). Additionally, the multiple variance ratio tests for the five periods are also carried out to jointly test the null 
hypothesis for the multiple individual periods. Since economic and financial time series data tend to have timevarying volatilities (Lo and MacKinlay, 1989) the heteroscedasticity robust random walk process is tested for the index and stock returns. The outputs of the multiple tests for the index return (Chow and Denning, 1993); (Richardson and Smith, 1991) along with individual tests, are presented in Table 4.

The Chow-Denning multiple tests (expressed as Joint Tests in Table 4) are the variance ratio tests of the joint null hypothesis for five periods, and the variance ratio tests for each individual periods are reported at the bottom of the table (expressed as Individual Tests). The maximum $|z|$ statistic of Chow-Denning tests, defined as $M_{2}$ in Equation (10), under the $15 \%$ price limits regime is 0.530 and p-value is 0.9893 . The null hypothesis of a random walk cannot be rejected. The individual statistics, defined as $Z_{2}$ in Equation (6), for all five periods, also cannot reject the null hypothesis as p-value is significantly greater than 0.05 . The results under the $30 \%$ price limits regime are reported in right-hand side and similar to those under the $15 \%$ price limits regime.

Furthermore, the individual and multiple variance ratio tests under the assumption of homoscedasticity are conducted and the results are reported in Table 5. The Chow-Denning maximum $|z|$ statistic, defined as $M_{1}$ in Equation (9), and the Richardson-Smith Wald test statistic, defined as $R S$ in Equation (11), for the joint hypotheses are obtained in addition to the individual test statistics, defined as $Z_{1}$ in Equation (4). The results are similar to the above heteroscedasticity robust tests for the KOSPI return series. The test results indicate that Korean stock market index follows the random walk process.

Table-4. Variance ratio tests for KOSPI (heteroscedasticity robust)

\begin{tabular}{|c|c|c|c|c|c|c|c|c|}
\hline \multicolumn{9}{|c|}{ Null Hypothesis: Log KOSPI is a martingale } \\
\hline & & \multicolumn{3}{|c|}{$15 \%$ price limits regime } & \multicolumn{4}{|c|}{$30 \%$ price limits regime } \\
\hline \multicolumn{2}{|c|}{ Joint Tests } & & & & & & & \\
\hline & & Value & df & Probability & & Value & df & Probability \\
\hline \begin{tabular}{l|l}
$\operatorname{Max} \mid z$ \\
$20) \mu$
\end{tabular} & (at period & 0.530025 & 849 & 0.9893 & & 0.988527 & 608 & 0.8577 \\
\hline \multicolumn{9}{|c|}{ Individual Tests } \\
\hline Period & Var. Ratio & Std. Error & z-Statistic & Probability & Var. Ratio & Std. Error & z-Statistic & Probability \\
\hline 2 & 0.991607 & 0.032826 & -0.25568 & 0.7982 & 1.024005 & 0.046775 & 0.513211 & 0.6078 \\
\hline 5 & 1.003745 & 0.081563 & 0.045919 & 0.9634 & 0.982631 & 0.106457 & -0.16316 & 0.8704 \\
\hline 10 & 0.961831 & 0.129035 & -0.2958 & 0.7674 & 0.843203 & 0.161262 & -0.97231 & 0.3309 \\
\hline 15 & 0.965247 & 0.162963 & -0.21325 & 0.8311 & 0.801874 & 0.200425 & -0.98853 & 0.3229 \\
\hline 20 & 0.898934 & 0.190681 & -0.53003 & 0.5961 & 0.850036 & 0.232998 & -0.64363 & 0.5198 \\
\hline
\end{tabular}

probability approximation using studentized maximum modulus (SMM) with parameter value 5 and infinite degrees of freedom.

Table-5. Variance ratio tests for KOSPI (homoscedasticity assumption)

\begin{tabular}{|c|c|c|c|c|c|c|c|c|}
\hline \multicolumn{9}{|c|}{ Null Hypothesis: Log KOSPI is a random walk } \\
\hline & & \multicolumn{3}{|c|}{$15 \%$ price limits regime } & \multicolumn{4}{|c|}{$30 \%$ price limits regime } \\
\hline \multicolumn{9}{|c|}{ Joint Tests } \\
\hline & & Value & df & Probability & & Value & df & Probability \\
\hline \multicolumn{2}{|c|}{$\begin{array}{l}\text { Max }|z| \text { (at period } \\
20)+\end{array}$} & 0.825914 & 849 & 0.9278 & & 1.362125 & 608 & 0.6135 \\
\hline \multicolumn{2}{|c|}{ Wald (Chi-Square) } & 7.396466 & 5 & 0.1928 & & 7.122531 & 5 & 0.2117 \\
\hline \multicolumn{9}{|c|}{ Individual Tests } \\
\hline Period & Var. Ratio & Std. Error & z-Statistic & Probability & Var. Ratio & Std. Error & z-Statistic & Probability \\
\hline 2 & 0.989271 & 0.03432 & -0.31262 & 0.7546 & 1.020637 & 0.040555 & 0.50886 & 0.6109 \\
\hline 5 & 0.994304 & 0.075191 & -0.07576 & 0.9396 & 0.969733 & 0.088852 & -0.34064 & 0.7334 \\
\hline 10 & 0.941535 & 0.115877 & -0.50454 & 0.6139 & 0.818404 & 0.136931 & -1.32619 & 0.1848 \\
\hline 15 & 0.933658 & 0.145787 & -0.45507 & 0.6491 & 0.765341 & 0.172274 & -1.36213 & 0.1732 \\
\hline 20 & 0.859126 & 0.170567 & -0.82591 & 0.4089 & 0.797696 & 0.201556 & -1.00371 & 0.3155 \\
\hline
\end{tabular}

The above processes are repeated for each of 60 sample stock returns to compare two different price limits periods and the results are summarized in Table 6, which shows the number of stocks rejecting the null hypothesis of random walk process along with percentage of companies following random walk out of 60 sample stocks, based on the Chow-Denning multiple variance ratio tests and Richardson-Smith Wald tests. Detailed results of multiple variance tests are reported in Appendix. For the period from January 2, 2012 to June 14, 2015 under the $15 \%$ price limits regime, the number of stocks rejecting the null hypothesis is 13 and slightly decreased to 10 for the period from June 15, 2015 to November 30, 2017 under the 30\% price limits regime, meaning that proportion of sample stock returns following the random walk process under the eased price limits regime slightly increased to $83.3 \%$ from the previous $15 \%$ regime of $78.3 \%$. This study is generally consistent with the findings of Ryoo and Smith (2002) that the Korean stock market becomes more efficient as the price limits are eased, albeit the findings are rather suggestive than definitive. However, homoscedastic Chow-Denning multiple variance ratio tests and Richardson-Smith Wald tests produced the different results. The proportion of sample stock returns following the random walk process under the eased price limits regime increased to $76.7 \%$ from the previous $15 \%$ regime of 63.3\% in homoscedastic Chow-Denning tests while Richardson-Smith Wald tests showed $75 \%$ up from $65 \%$ under the previous regime. When significance level is applied at $10 \%$, the difference is more noticeable as random walk proportion was found to increase from $66.7 \%$ to $80 \%, 56.7 \%$ to $70 \%$ and $48.3 \%$ to $68.3 \%$ based on three different multiple variance ratio tests, respectively. 
Table-6. Results of multiple variance ratio tests for 60 stock returns

\begin{tabular}{l|c|c|c}
\hline & No of Rejected Null at 5\% significance (Percentage of random walk process) \\
\hline & \multicolumn{2}{|c|}{ Chow-Denning tests } & \multicolumn{2}{c}{ Richardson-Smith tests } \\
\hline & Heteroscedasticity robust & $\begin{array}{c}\text { Homoscedasticity } \\
\text { assumption }\end{array}$ & Wald tests \\
\hline $15 \%$ regime & $13(78.3 \%)$ & $22(63.3 \%)$ & $21(65 \%)$ \\
\hline $30 \%$ regime & $10(83.3 \%)$ & $14(76.7 \%)$ & $15(75 \%)$ \\
\hline
\end{tabular}

\begin{tabular}{l|c|c|c}
\hline & No of Rejected Null at 10\% significance (Percentage of random walk process) \\
\hline & \multicolumn{2}{|c}{ Chow-Denning tests } & Richardson-Smith tests \\
\hline & Heteroscedasticity robust & $\begin{array}{c}\text { Homoscedasticity } \\
\text { assumption }\end{array}$ & Wald tests \\
\hline $15 \%$ regime & $20(66.7 \%)$ & $26(56.7 \%)$ & $31(48.3 \%)$ \\
\hline $30 \%$ regime & $12(80 \%)$ & $18(70 \%)$ & $19(68.3 \%)$ \\
\hline \multicolumn{2}{l|}{ Note: Wald test is only used for homoscedasticity assumption because this method is not consistent with the heteroscedasticity robust tests }
\end{tabular}

(QMS, 2010).

In addition, to identify the effect of market capitalisation on the market efficiency to find out the answer to the common hypothesis that large capitalisation stocks tend to more follow the random walk process than small capitalisation stocks, we divided the sample stocks into two groups in terms of market capitalisation for comparison. The 30 large-cap stocks have the average market capitalisation of 25,266 million dollars in stark contrast to 2,369 million dollars of that of the 30 sample-cap stocks. Under the $15 \%$ price limits regime, 47 stocks following a random walk consist of 22 large-cap and 25 small-cap stocks while 50 stocks following a random walk include 23 large-cap and 27 small-cap stocks suggesting that market capitalisation does not play a significant role in the market efficiency.

\section{Conclusions}

This study examined the efficiency of Korean stock market, within the framework of a random walk model, to compare the results before and after a substantial relaxation of daily price limits effective on June 15, 2015. ChowDenning and Richardson-Smith multiple variance ratio tests have been employed to find out the effect of expansion of price limits on the market efficiency.

The daily returns for the Korean stock market index and 60 stocks listed in the Korea Exchange were examined over the period from January 2, 2012 to November 30, 2017 which was divided into two sub-periods i.e., period from January 2, 2012 to June 14, 2015 and period from June 15, 2015 to November 30, 2017 for the comparison purpose. The sample stocks were selected from different industries to represent well the stock market.

According to the results of the tests, the daily return of KOSPI, the Korean market index, followed the random walk process for both the periods under the $15 \%$ and $30 \%$ price limits. For the returns of sample stocks, the number of stocks following random walk hypothesis slightly increased from 47 stocks $(78.3 \%)$ under $15 \%$ price limits to 50 stocks $(83.3 \%)$ under $30 \%$ price limits in the heteroscedasticity robust tests. Based on the homoscedasticity assumption tests and Wald tests, the number of stocks accepting the null of random walk hypothesis increased from 38 stocks $(63.3 \%)$ and $39(65 \%)$ under $15 \%$ price limits to 46 stocks $(76.7 \%)$ and $45(75 \%)$ under $30 \%$ price limits, respectively. Overall findings suggested that within the framework of a random walk model, the market index showed market efficiency in a weak form during both two sub-periods. Individual stock returns do not behave in the same way as that of the market index in terms of the random walk possibly because information is processed differently across individual companies and their stocks. However, this study suggests, daily returns in more stocks in the Korean stock market appear to behave in weak form efficient way as the price limits are eased.

In view of the findings in this study and the resilience the stock market has shown since the substantial relaxation of daily price limits, it seems that consideration should be given for the price limits to be removed completely further down the line to enhance the informational efficiency of the country's stock market so as to be on a par with well-developed global stock markets.

\section{References}

Amélie, C. and O. Darné, 2009. Variance-ratio tests of random walk: An overview. Journal of Economic Surveys, 23(3): 503-527. Available at: https://doi.org/10.1111/j.1467-6419.2008.00570.x.

Ayadi, O.F. and C.S. Pyun, 1994. An application of variance ratio test to the Korean securities market. Journal of Banking \& Finance, 18(4): 643-658. Available at: https://doi.org/10.1016/0378-4266(94)00012-3.

Berkman, H. and J.B.T. Lee, 2002. The effectiveness of price limits in an emerging market: Evidence from the Korean stock exchange. Pacific-Basin Finance Journal, 10(5): 517-530. Available at: https://doi.org/10.1016/s0927-538x(02)00040-9.

Chow, K.V. and K.C. Denning, 1993. A simple multiple variance ratio test. Journal of Econometrics, 58(3): 385-401. Available at: https://doi.org/10.1016/0304-4076(93)90051-6.

Fama, E.F., 1965. The behavior of stock-market prices. The Journal of Business, 38(1): 34-105. Available at: https://doi.org/10.1086/294743.

Fama, E.F., 1970. Efficient capital markets: A review of theory and empirical work. The Journal of Finance, 25(2): 383-417. Available at: https://doi.org/10.2307/2325486.

Fama, E.F., 1991. Efficient capital markets: II. The Journal of Finance, 46(5): 1575-1617.Available at: https://doi.org/10.2307/2328565.

Fong, W.M., S.K. Koh and S. Ouliaris, 1997. Joint variance-ratio tests of the martingale hypothesis for exchange rates. Journal of Business \& Economic Statistics, 15(1): 51-59. Available at: https://doi.org/10.2307/1392073.

Hasanov, M., 2009. Is South Korea's stock market efficient? Evidence from a nonlinear unit root test. Applied Economics Letters, 16(2): 163167. Available at: https://doi.org/10.1080/13504850601018270.

Hoque, H.A., J.H. Kim and C.S. Pyun, 2007. A comparison of variance ratio tests of random walk: A case of Asian emerging stock markets. International Review of Economics \& Finance, 16(4): 488-502. Available at: https://doi.org/10.1016/j.iref.2006.01.001.

Huang, B.-N., 1995. Do Asian stock market prices follow random walks? Evidence from the variance ratio test. Applied Financial Economics, 5(4): 251-256. Available at: https://doi.org/10.1080/758536875.

Kim, J.H. and A. Shamsuddin, 2008. Are Asian stock markets efficient? Evidence from new multiple variance ratio tests. Journal of Empirical Finance, 15(3): 518-532. Available at: https://doi.org/10.1016/j.jempfin.2007.07.001. 
Lee, S.B. and J.S. Chung, 1996. Price limits and stock market efficiency. Journal of Business Finance \& Accounting, 23(4): 585-601. Available at: https://doi.org/10.1111/j.1468-5957.1996.tbo1027.x

Lee, S.B. and K.J. Kim, 1995. The effect of price limits on stock price volatility: Empirical evidence in Korea. Journal of Business Finance \& Accounting, 22(2): 257-267. Available at: https://doi.org/10.1111/j.1468-5957.1995.tbo0682.x.

Lim, K.-P. and R.D. Brooks, 2009. Price limits and stock market efficiency: Evidence from rolling bicorrelation test statistic. Chaos, Solitons \& Fractals, 4O(3): 1271-1276. Available at: https://doi.org/10.1016/j.chaos.2007.09.001.

Lo, A.W. and A.C. MacKinlay, 1988. Stock market prices do not follow random walks: Evidence from a simple specification test. The Review of Financial Studies, 1(1): 41-66. Available at: https://doi.org/10.1093/rfs/1.1.41.

Lo, A.W. and A.C. MacKinlay, 1989. The size and power of the variance ratio test in finite samples: A Monte Carlo investigation. Journal of Econometrics, 40(2): 203-238. Available at: https://doi.org/10.1016/0304-4076(89)90083-3.

Malkiel, B.G. and E.F. Fama, 1970. Efficient capital markets: A review of theory and empirical work. The Journal of Finance, $25(2): 383-417$. Available at: https://doi.org/10.2307/2325486.

Narayan, P.K. and R. Smyth, 2004. Is South Korea's stock market efficient? Applied Economics Letters, 11(11): 707-710. Available at: https://doi.org/10.1080/1350485042000236566.

QMS, 2010. Eviews 7 user's guide. Irvine: Quantitative Micro Software.

Richardson, M. and T. Smith, 1991. Tests of financial models in the presence of overlapping observations. The Review of Financial Studies, 4(2): 227-254. Available at: https://doi.org/10.1093/rfs/4.2.227

Ryoo, H.-J. and G. Smith, 2002. Korean stock prices under price limits: Variance ratio tests of random walks. Applied Financial Economics, 12(8): 545-553. Available at: https://doi.org/10.1080/09603100010015789.

Appendix Multiple variance ratio test statistics for 60 sample stock returns

\begin{tabular}{|c|c|c|c|c|c|c|}
\hline \multirow[b]{3}{*}{ Companies } & \multicolumn{2}{|c|}{ Heteroscedastic statistic } & \multicolumn{2}{|c|}{ Homoscedastic statistic } & \multirow{2}{*}{\multicolumn{2}{|c|}{$\begin{array}{l}\text { Wald } \\
\text { Chi-Square }\end{array}$}} \\
\hline & \multicolumn{4}{|c|}{ Max $|z|($ at period $m) \psi$} & & \\
\hline & $15 \%$ regime & $30 \%$ regime & $15 \%$ regime & $30 \%$ regime & $15 \%$ regime & $30 \%$ regime \\
\hline CHEILWORLDWIDE & 1.830471 & $2.98077^{* * *}$ & $2.31569^{*}$ & $3.296791^{* * * *}$ & 7.454514 & $14.06022 * *$ \\
\hline CJCHEILJEDANG & 1.400717 & 1.525446 & 1.501797 & 1.902277 & 7.186084 & 7.684503 \\
\hline DAELIM & 0.926926 & 1.83969 & 1.027427 & 2.01704 & 3.467691 & $11.23829 * *$ \\
\hline DAEWOOENGCON & 1.921652 & 0.762597 & $2.395033^{*}$ & 1.012034 & $10.90901 *$ & 2.499223 \\
\hline DAEWOONGPHARM & 0.950224 & 0.922933 & 1.454914 & 1.294702 & 3.298798 & 6.867637 \\
\hline DONGKUKSTEEL & $2.539775^{*}$ & 1.079783 & $2.605329^{* *}$ & 0.700443 & $11.56606^{* * *}$ & 2.307117 \\
\hline DOOSANHEAVY & 1.397336 & 0.862376 & 1.503681 & 0.923065 & 2.458352 & 1.97465 \\
\hline DOOSANINFRACORE & 1.078199 & 0.930743 & 0.934098 & 0.722355 & 4.21221 & 6.382559 \\
\hline E-MART & $3.209016^{* * *}$ & 1.551378 & $3.327977^{*} * *$ & 1.771856 & $12.45615^{* *}$ & 3.343391 \\
\hline GREENCROSS & $2.537801^{*}$ & 1.10672 & $3.686419^{* * * *}$ & 1.736259 & $19.91317^{* * * *}$ & 5.415741 \\
\hline GSENGCON & $3.110408 * * *$ & 1.879613 & $3.643245^{* * * *}$ & 2.15631 & $15.82106^{* * * *}$ & 6.161089 \\
\hline HANKOOKCOS & $2.508704^{*}$ & 1.094399 & $4.237859^{* * * *}$ & $2.434904 *$ & $21.34202^{* * * *}$ & $18.07949 * * *$ \\
\hline HANMIPHARM & $3.174363^{* * *}$ & 1.572038 & $4.182833^{* * * *}$ & 2.275697 & $23.43258 * * *$ & $12.17233^{* * *}$ \\
\hline HANONSYSTEMS & $4.291285^{* * * *}$ & $2.90924^{* * *}$ & $5.107231 * * *$ & $3.083673^{* * *}$ & $27.14011 * * *$ & $9.661571^{*}$ \\
\hline HANWHALIFE & $4.259112^{* * *}$ & $2.648061 * *$ & $4.831154^{* * * *}$ & $3.19802^{*} * *$ & $27.61024^{* * * *}$ & $10.86202^{*}$ \\
\hline HOTELSHILLA & 1.573146 & $2.336372^{*}$ & 1.907031 & 2.238132 & $10.79997 *$ & $9.961223^{*}$ \\
\hline HYOSUNG & 1.8139 & $3.002945^{* * *}$ & 2.163361 & $3.479095 * * *$ & $10.01349^{*}$ & $14.19565 * *$ \\
\hline HYUNDAIELEVATOR & $2.463976^{*}$ & 2.092203 & 3.771594 **** & $2.422467 *$ & $20.68373 * * *$ & $16.40827 * * *$ \\
\hline HYUNDAIENGCON & 0.717199 & 1.144545 & 0.561167 & 1.399212 & 1.926149 & 3.84586 \\
\hline HYUNDAIGLOVIS & 2.203864 & 2.165131 & $2.606913^{* *}$ & $2.434932^{*}$ & $10.67691^{*}$ & 8.966991 \\
\hline HYUNDAIMOBIS & $2.313648 *$ & 1.071227 & $2.525827 *$ & 1.23627 & $10.57079^{*}$ & 4.604662 \\
\hline HYUNDAIMOTOR & 2.087575 & 1.152455 & 2.124651 & 1.411901 & $12.46144^{* *}$ & 5.488485 \\
\hline HYUNDAISTEEL & 0.682776 & 1.868506 & 0.907463 & 1.873965 & 2.071319 & 4.860405 \\
\hline HYUNDAISTORE & 1.626004 & 1.682304 & 1.942525 & 1.970486 & 5.287735 & 6.097439 \\
\hline KAKAO & 1.060967 & 1.264343 & 1.691145 & 1.361967 & 7.611878 & 7.74993 \\
\hline KAL & 0.692759 & 1.055248 & 0.777423 & 1.32823 & 3.041238 & 8.90783 \\
\hline KANGWONLAND & $5.342544^{* * * *}$ & $4.096564^{* * * *}$ & $6.025009 * * *$ & $4.907403 * * *$ & $36.98488^{* * * *}$ & 25.43356 *** \\
\hline KBFIN & 0.893272 & 1.531725 & 1.09417 & 1.724666 & 6.929764 & 6.658761 \\
\hline KEPCO & 1.242672 & 1.006188 & 1.472569 & 1.248996 & 4.433857 & 4.28597 \\
\hline KIAMOTORS & 1.100244 & 2.301497 & 1.257512 & 2.402959* & 3.812318 & 9.03386 \\
\hline KOREAAEROSPACE & $2.481467 *$ & 0.720739 & $2.958371 * *$ & 1.119777 & $10.47648^{*}$ & 3.646556 \\
\hline KOREAGAS & 0.909882 & 0.87493 & 0.944601 & 1.213744 & 2.659921 & 2.971023 \\
\hline KOREAZINC & 1.493785 & 1.790442 & 1.756351 & 2.075135 & 3.762902 & 6.591293 \\
\hline KT & $3.115139 * * *$ & 0.617785 & $3.334546^{* * * *}$ & 0.760366 & $18.86552^{* * * *}$ & 3.220231 \\
\hline KT\&G & $3.070249 * *$ & $3.396537 * * *$ & $3.586073^{* * * *}$ & $3.821462 * * *$ & $22.9986 * * *$ & $16.3575 * * *$ \\
\hline LFCORP & 2.234635 & $4.301014^{* * * *}$ & $2.391303^{*}$ & $5.30149 * * *$ & 6.443256 & $31.90549 * * *$ \\
\hline LGCHEM & 2.103715 & 1.676146 & 1.923756 & 1.917326 & $10.07772 *$ & 4.39537 \\
\hline LGELECT & 0.601538 & 2.197447 & 0.592522 & 2.133737 & 4.623386 & 6.028885 \\
\hline LOTTECHEM & 1.951746 & $2.800803 * *$ & 1.694539 & $2.941596^{* * *}$ & 5.402075 & 8.893145 \\
\hline LOTTESHOPPING & 0.941289 & 1.708618 & 1.177646 & 2.159162 & 4.201193 & $18.91795 * * *$ \\
\hline MIRAEASSET & 1.95235 & 1.645519 & 2.026068 & 1.846841 & $12.36496^{* * *}$ & $10.90002 *$ \\
\hline NAVER & $2.478585^{*}$ & 1.940929 & $4.9703 * * *$ & 2.070704 & $27.6874 * * *$ & 6.939239 \\
\hline NCSOFT & 0.383054 & $2.744801 * *$ & 0.564089 & $3.084269^{* *}$ & 1.795207 & $12.34522^{* *}$ \\
\hline NONGSHIM & $3.512174^{* * * *}$ & 2.205882 & $4.255583^{* * * *}$ & $2.903073^{* *}$ & $19.33253 * * *$ & 8.879528 \\
\hline OTTOGI & 0.889206 & 0.980894 & 1.06053 & 1.402369 & 6.037349 & 7.849578 \\
\hline POSCO & 0.509972 & 1.710562 & 0.805075 & 1.833721 & 2.642859 & 6.835128 \\
\hline S-OIL & 0.779485 & $2.436092^{*}$ & 0.673538 & $2.59231 * *$ & 1.433071 & $11.92663^{* *}$ \\
\hline SAMSUNGELECT & 1.430405 & 1.542095 & 1.620774 & 1.784725 & 8.869967 & $14.86456^{* *}$ \\
\hline SAMSUNGHEAVY & 1.403647 & 0.380853 & 1.620409 & 0.579986 & 3.548904 & 1.883451 \\
\hline SAMSUNGLIFE & $3.490284 * * *$ & $3.124508 * * *$ & $4.276263^{* * * *}$ & $3.280744^{* * * *}$ & $19.42029 * * *$ & $12.61047 * *$ \\
\hline SAMYANG & $3.013633 * *$ & 1.177964 & $5.545115^{* * * *}$ & 1.911286 & $43.77612^{* * * *}$ & 7.858755 \\
\hline SHINHANFIN & 1.647953 & 2.292464 & 1.867316 & $2.583072^{* *}$ & 8.030287 & 8.490821 \\
\hline SHINSEGAE & 0.666579 & 1.12446 & 0.969206 & 1.530295 & 3.790255 & 5.069083 \\
\hline SINDOHCO & $3.680686^{* * *}$ & 0.779974 & $4.544415^{* * * *}$ & 1.050148 & $24.58498 * * *$ & 4.201971 \\
\hline
\end{tabular}


Asian Journal of Economics and Empirical Research, 201 8, 5(2): 191-200

\begin{tabular}{l|l|l|l|l|l|l}
\hline SKHYNIX & $2.780166^{* *}$ & 2.006817 & $3.005425^{* *}$ & 2.263952 & $9.973038^{*}$ & 6.32449 \\
\hline SKTELECOM & 1.768145 & 1.342539 & 1.996377 & 1.591287 & $10.96239^{*}$ & 2.616864 \\
\hline SSANGYONGCEMENT & 0.874101 & 0.302373 & 0.734473 & 0.602898 & 3.621956 & 0.839615 \\
\hline TAIHANELECT & 1.918576 & 1.584975 & $2.621028^{* *}$ & $5.773004^{* * *}$ & $15.15008^{* * *}$ & $41.87059^{* * *}$ \\
\hline WOORIBK & 0.812129 & 0.91053 & 1.297525 & 1.012803 & $12.15334^{* *}$ & 1.782574 \\
\hline YUHAN & 2.27097 & 1.150643 & $2.718627^{* *}$ & 1.396158 & $9.354121^{*}$ & 3.275828 \\
\hline No of Null rejected & $13(20$ at 0.1$)$ & $10(12$ at 0.1$)$ & $22(26$ at 0.1$)$ & $14(18$ at 0.1$)$ & $21(31$ at 0.1$)$ & $15(19$ at 0.1$)$ \\
\hline
\end{tabular}

$\uparrow$ Probability approximation using studentized maximum modulus (SMM) with parameter value 5 and infinite degrees of freedom.

*, ** and *** indicate significance at the $10 \%, 5 \%$ and $1 \%$, respectively. 